\title{
Patient-directed therapy during in-patient stroke rehabilitation: stroke survivors' views of feasibility and acceptability
}

DOI:

10.3109/09638288.2015.1024341

Link to publication record in Manchester Research Explorer

Citation for published version (APA):

Horne, M., Thomas, N., McCabe, C., Selles, R., Vail, A., Tyrrell, P., \& Tyson, S. (2015). Patient-directed therapy during in-patient stroke rehabilitation: stroke survivors' views of feasibility and acceptability. Disability and Rehabilitation, 37(25), 2344-2349. https://doi.org/10.3109/09638288.2015.1024341

Published in:

Disability and Rehabilitation

\section{Citing this paper}

Please note that where the full-text provided on Manchester Research Explorer is the Author Accepted Manuscript or Proof version this may differ from the final Published version. If citing, it is advised that you check and use the publisher's definitive version.

\section{General rights}

Copyright and moral rights for the publications made accessible in the Research Explorer are retained by the authors and/or other copyright owners and it is a condition of accessing publications that users recognise and abide by the legal requirements associated with these rights.

\section{Takedown policy}

If you believe that this document breaches copyright please refer to the University of Manchester's Takedown Procedures [http://man.ac.uk/04Y6Bo] or contact uml.scholarlycommunications@manchester.ac.uk providing relevant details, so we can investigate your claim.

\section{OPEN ACCESS}




\title{
Disability and Rehabilitation
}

\section{Patient-directed therapy during in-patient stroke rehabilitation: stroke survivors' views of feasibility and acceptability}

\author{
Maria Horne, Nessa Thomas, Candy McCabe, Rudd Selles, Andy Vail, Pippa \\ Tyrrell \& Sarah Tyson
}

To cite this article: Maria Horne, Nessa Thomas, Candy McCabe, Rudd Selles, Andy Vail, Pippa Tyrrell \& Sarah Tyson (2015) Patient-directed therapy during in-patient stroke rehabilitation: stroke survivors' views of feasibility and acceptability, Disability and Rehabilitation, 37:25, 2344-2349, DOI: 10.3109/09638288.2015.1024341

To link to this article: http://dx.doi.org/10.3109/09638288.2015.1024341

曲 Published online: 28 Apr 2015.

Submit your article to this journal $₫$

Џ Article views: 69

Q View related articles $\sqsubset$

View Crossmark data 5 


\title{
Patient-directed therapy during in-patient stroke rehabilitation: stroke survivors' views of feasibility and acceptability
}

\author{
Maria Horne ${ }^{1}$, Nessa Thomas ${ }^{2,3}$, Candy McCabe ${ }^{4,5}$, Rudd Selles ${ }^{6,7}$, Andy Vail ${ }^{2,8}$, Pippa Tyrrell ${ }^{2,8}$, and Sarah Tyson ${ }^{2,3}$ \\ ${ }^{1}$ School of Health, University of Bradford, Bradford, UK, ${ }^{2}$ Stroke Research Centre, Manchester Academic Health Sciences Centre, ${ }^{3}$ School of Nursing, \\ Midwifery \& Social Work, University of Manchester, Manchester, UK, ${ }^{4}$ School of Nursing, University of the West England, Bristol, UK, ${ }^{5}$ Royal National \\ Hospital for Rheumatic Diseases NHS Foundation Trust, Bath, UK, ${ }^{6}$ Department of Plastic, Reconstructive and Hand Surgery, and ${ }^{7}$ Department of \\ Rehabilitation Medicine \& Physical Therapy, Erasmus University, Rotterdam, The Netherlands, and ${ }^{8}$ Salford Royal NHS Foundation Trust, Salford, UK
}

\begin{abstract}
Purpose: Patient-led therapy, in which patients work outside therapy sessions without direct supervision, is a possible way to increase the amount of therapy stroke patients' receive without increasing staff demands. Here, we report patients' views of patient-led mirror therapy and lower limb exercises. Method: 94 stroke survivors with upper and lower limb limitations at least 1-week post-stroke undertook 4 weeks of daily patient-led mirror therapy or lower limb exercise, then completed questionnaires regarding their experience and satisfaction. A convenience random sample of 20 participants also completed a semi-structured telephone interview to consider their experience in more detail and to capture their longer term impressions. Results: Participants were generally positive about patient-led therapy. About $71 \%$ found it useful; $68 \%$ enjoyed it; $59 \%$ felt it "worked" and $88 \%$ would recommend it to other patients. Exercise was viewed more positively than the mirror therapy. Difficulties included arranging the equipment and their position, particularly for more severe strokes, loss of motivation and concerns about working unsupervised. Conclusions: Patient-led mirror therapy and lower limb exercises during in-patient rehabilitation is generally feasible and acceptable to patients but "light touch" supervision to deal with any problems, and strategies to maintain focus and motivation are needed.

\section{> Implications for Rehabilitation}

- Most stroke patients receive insufficient therapy to maximize recovery during rehabilitation. As increases in staffing are unlikely there is an imperative to find ways for patients to increase the amount of exercise and practice of functional tasks they undertake without increasing demands on staff.

- Patient-led therapy (also known as patient-directed therapy or independent practice), in which patients undertake exercises or functional tasks practice prescribed by a professional outside formal therapy sessions is one way of achieving this. It is widely used in communitybased rehabilitation but is uncommon in hospital-based stroke care.

- We explored the feasibility and acceptability of two types of patient-led therapy during hospital-based stroke care; mirror therapy for the upper limb and exercises (without a mirror) for the lower limb. Here, we report patients' experiences of undertaking patient-led therapy.

- Patient-led mirror therapy and lower limb exercises during in-patient stroke rehabilitation is generally feasible and acceptable to patients but "light touch" supervision to deal with any problems, and strategies to maintain focus and motivation are needed.
\end{abstract}

\section{Keywords}

Exercise, mirror therapy, patient led therapy, patients views, stroke

\section{History}

Received 8 September 2014

Revised 12 February 2015

Accepted 25 February 2015

Published online 13 March 2015

\section{Introduction}

It is well-established that therapy focussing on intensive practice of functional tasks is key to regaining motor skills after stroke $[1,2]$ but enabling stroke survivors to undertake sufficient practice

Address for correspondence: Sarah Tyson, Stroke Research Centre, University of Manchester, Jean McFarlane Building, Oxford Road, Manchester M13 9PL, UK. Tel: +0 441613067781. E-mail: sarah.tyson@manchester.ac.uk is a challenge, particularly in the early stages of recovery while patients are in hospital. During this time, few patients receive the "dose" of therapy recommended in National Clinical Guidelines. In the UK, e.g. " at least 45 minutes of each discipline per day" is recommended but rarely achieved [3]. This appears to be a widespread problem as surveys in several countries have shown most stroke patients spend most of their hospital-based rehabilitation unoccupied and alone [4-8].

Lack of therapists to deliver sufficient therapy may be an obvious explanation, and there is some support for this view; few 
stroke services in UK have sufficient specialist staff to meet national recommendations [3,9]. However, in the current financial climate, substantial increases in therapist staffing levels are unlikely. Consequently, alternative methods are needed to increase the amount of therapy without increasing staff demands. One possibility is "patient-led therapy" where patients work on tasks or exercises prescribed by a health care professional but without direct supervision. This is common practice in community-based rehabilitation and exercise regimen, but is rarely attempted during in-patient rehabilitation $[4,5,10,11]$.

The aim of this study was to assess stroke survivors' views and experiences of two patient-led therapies; mirror therapy and lower limb exercises. This was as part of a randomized controlled trial to assess the feasibility and acceptability of these interventions (URL: http://www.controlled-trials.com Unique identifier: ISRCTN29533052) called the Mirror Arm Exercises for Stroke (MAESTRO) trial. The effects of the interventions on impairments and activity imitations; adherence to the intervention; factors influencing adherence; adverse events and staff's experience of delivering patient-led therapy are reported elsewhere $[12,13]$.

\section{Methods}

Approval was obtained from the Local Committee of the National Research Ethics Service. Stroke survivors were recruited to the trial if they were at least 1-week post-stroke, undergoing inpatient rehabilitation, had limited upper and lower limb function, were previously independent and able to consent. They were randomized to receive usual care plus either patent-led mirror therapy or the attentional control (patient-led lower limb exercises) in a 2:1 allocation. Details of the interventions have been published [12] previously. As there were no previously reported data for patient-led mirror therapy during acute stroke, a formal power calculation was not appropriate. Instead, we recruited sufficient numbers to enable a sufficiently precise estimate of the variability (SD) of study endpoints for future sample size calculations and sufficient replications of the protocol to assess feasibility. At least 55 participants recruited to the mirror therapy would enable these objectives including a 10\% drop-out. As randomisation to a control may be problematic and to allow initial evaluation of effect, we also included a control group using a 2:1 allocation ratio (mirror: control).

Appropriate individualized exercises and activities were selected for each participant who were taught how to perform the interventions by the research and clinical teams. Instructions with photographs for each exercise were compiled into a booklet to act as an aide-memoire. Participants were asked to undertake the treatment for up to $30 \mathrm{~min} / \mathrm{day}$, every day for 28 days. A member of the clinical team briefly checked on them each day, progressed the exercises as necessary and dealt with any difficulties.

Participants' views and experiences of the therapies were assessed at the end of treatment (4 weeks after baseline) using a semi-structured questionnaire, which was developed with the trial's stroke survivors' consultation group. It consisted of open and closed questions using dichotomous or Likert scale responses with space for free text where participants were invited to add any other thoughts, experiences or comments they would like us to know. It was completed by the patient with assistance from a relative or a member of the research team, if necessary.

To explore stroke survivors' longer term views (rather than immediately after the end of the treatment), we also undertook semi-structured telephone interviews with a convenience sample of participants who had completed their follow up assessments (4 weeks after the end of treatment) [14]. At the follow up assessment, participants were invited to be interviewed to explore their views and experience of patient-led therapy in more detail. Those who were interested were given further details and a patient information sheet. They were telephoned a few days later to confirm whether they wished to take part, and if so, a convenient time was arranged to conduct the interview. These lasted 30-45 min and were undertaken by $\mathrm{MH}$ and two research therapists who were independent of the main trial. Recruitment continued until data saturation occurred [15]. The interview guide is found in Appendix 1.

\section{Analysis}

Data from the questionnaires were analysed using descriptive statistics and thematic content analysis of the open questions [16]. Responses were counted and exact words were highlighted to capture key concepts and themes [16]. The interviews were audiorecorded, transcribed verbatim and anonymized and analysed using a framework approach [17].

Data analysis and classification followed a Framework Approach using NVIVO10 qualitative analysis software programme for data coding, cross-referencing, storage and retrieval. There are five key stages to the analysis: familiarisation; identification of the thematic framework; indexing; charting; mapping and interpretation. During the familiarisation, the recordings and transcripts were listened to and read several times by the main authors (MH, NT, ST) to become immersed with the data. A thematic framework was developed by reviewing the notes developed during the familiarisation process and identifying key themes and sub-themes to create a hierarchical framework. The framework was then systematically applied to all the data (known as indexing), concurrently modifying and refining the framework to maximize the grounding of the framework in the data. A series of thematic charts were subsequently devised with indexed data entered into an appropriate cell (charting) to establish the interconnectedness of the themes. This stage assisted the mapping and interpretation, which involved identification of patterns and key issues by making comparisons and developing explanations that were grounded in the data.

\section{Results}

Ninety-four participants were recruited to the trial [median age 66 years (range $=26-92) ; 65 \%$ men; $41 \%$ right-sided weakness and median time since stroke $=19$ days (range 7-133)]. Twenty participants (14 men, 10 with a left-sided weakness) took part in the interviews. Median age was 62.5 years (range 38-84 years). Five had a mild weakness (Motricity Index score $=67-100$ ); 10 had a moderate weakness (Motricity Index score $=33-66$ ) and five had a severe weakness (Motricity Index $=0-32$ ) at baseline assessment. Characteristics of individual interviewees are shown in Table 1.

Participants' responses to patient-led therapy in the questionnaires were generally positive (Table 2). About $71 \%$ found it useful and 68\% of respondents enjoyed doing it. About 94\% understood how to do the therapy and $69 \%$ could manage to do it; $59 \%$ felt that the therapy "worked"; $50 \%$ reported that they continued the therapy after completion of the intervention period and $88 \%$ would recommend it to other stroke survivors. There were differences between the mirror therapy and the lower limb exercises groups with participants consistently rating the exercises slightly more positively than the mirror therapy. This was most marked in their views of whether the therapy "worked" (75\% versus 53\%, respectively); recommendation to other stroke survivors (96\% versus $86 \%$, respectively) and difficulty getting started ( $12 \%$ versus $42 \%$, respectively) 
Table 1. Details of participants who took part in the interviews.

\begin{tabular}{|c|c|c|c|c|}
\hline $\begin{array}{l}\text { Participant } \\
\text { identifier number }\end{array}$ & Age & Sex & $\begin{array}{l}\text { Side of } \\
\text { hemiplegia }\end{array}$ & $\begin{array}{l}\text { Severity of } \\
\text { weakness }\end{array}$ \\
\hline 51 & 78 & M & Right & Mild \\
\hline 61 & 48 & M & Right & Severe \\
\hline 19 & 84 & M & Right & Mild \\
\hline 87 & 50 & M & Left & Severe \\
\hline 22 & 54 & M & Right & Severe \\
\hline 12 & 38 & $\mathrm{M}$ & Left & Moderate \\
\hline 16 & 76 & M & Left & Moderate \\
\hline 6 & 39 & $\mathrm{~F}$ & Right & Moderate \\
\hline 3 & 58 & M & Right & Mild \\
\hline 50 & 63 & M & Left & Moderate \\
\hline 38 & 66 & $\mathrm{~F}$ & Left & Moderate \\
\hline 39 & 78 & M & Left & Severe \\
\hline 70 & 74 & M & Left & Mild \\
\hline 45 & 67 & $\mathrm{~F}$ & Left & Moderate \\
\hline 76 & 58 & M & Left & Moderate \\
\hline 54 & 66 & M & Right & Moderate \\
\hline 34 & 55 & M & Right & Mild \\
\hline 62 & 62 & M & Right & Moderate \\
\hline 63 & 67 & $\mathrm{~F}$ & Left & Moderate \\
\hline 84 & 61 & M & Right & Moderate \\
\hline
\end{tabular}

Table 2. Stroke survivors' views of patient-directed therapy $(n=78)$.

\begin{tabular}{|c|c|c|c|}
\hline & No & Not sure & Yes \\
\hline \multicolumn{4}{|c|}{ Did you find the therapy useful? } \\
\hline Exercises & $2(7 \%)$ & $4(14 \%)$ & $22(79 \%)$ \\
\hline Mirror therapy & $7(15 \%)$ & $7(15 \%)$ & $33(70 \%)$ \\
\hline Overall & $9(12 \%)$ & $11(14 \%)$ & $55(71 \%)$ \\
\hline \multicolumn{4}{|c|}{ Did you enjoy doing the therapy? } \\
\hline Exercises & $4(14 \%)$ & $3(11 \%)$ & $21(75 \%)$ \\
\hline Mirror therapy & $10(22 \%)$ & $4(9 \%)$ & $32(68 \%)$ \\
\hline Overall & $14(18 \%)$ & $7(9 \%)$ & $53(68 \%)$ \\
\hline \multicolumn{4}{|c|}{ Could you understand the therapy? } \\
\hline Exercises & $1(4 \%)$ & Not asked & $27(96 \%)$ \\
\hline Mirror therapy & $4(8 \%)$ & & $46(92 \%)$ \\
\hline Overall & $5(6 \%)$ & & $73(94 \%)$ \\
\hline \multicolumn{4}{|c|}{ Do you think the therapy worked? } \\
\hline Exercises & $2(7 \%)$ & $5(18 \%)$ & $21(75 \%)$ \\
\hline Mirror therapy & $3(6 \%)$ & $19(40 \%)$ & $25(53 \%)$ \\
\hline Overall & $5(6 \%)$ & $24(31 \%)$ & $46(59 \%)$ \\
\hline \multicolumn{4}{|c|}{ Have you continued to do the therapy after the treatment period? } \\
\hline Exercises & $6(25 \%)$ & Not asked & $18(75 \%)$ \\
\hline Mirror therapy & $26(55 \%)$ & & $21(45 \%)$ \\
\hline Overall & $32(41 \%)$ & & $39(50 \%)$ \\
\hline \multicolumn{4}{|c|}{ Would you recommend the therapy to other stroke survivors? } \\
\hline Exercises & $1(4 \%)$ & $0(0 \%)$ & $26(96 \%)$ \\
\hline Mirror therapy & $2(4 \%)$ & $5(10 \%)$ & $43(86 \%)$ \\
\hline Overall & $3(4 \%)$ & $5(6 \%)$ & $69(88 \%)$ \\
\hline \multicolumn{4}{|c|}{ Did you have problems getting started? } \\
\hline Exercises & $22(88 \%)$ & Not asked & $3(12 \%)$ \\
\hline Mirror therapy & $28(58 \%)$ & & $20(42 \%)$ \\
\hline Overall & $50(64 \%)$ & & $23(29 \%)$ \\
\hline
\end{tabular}

Three main themes emerged from the open comments in the questionnaires and the interviews: the benefits of patent-led therapy; practical difficulties and solutions, barriers to patient-led therapy.

\section{Benefits of patient-led therapy}

Although many found it difficult to distinguish the effect of the self-directed therapy from other aspects of treatment, the most frequent response was that it improved recovery:

I started using it [the mirror] and I have to say I was quite amazed because there were flickers in the left upper arm and the left forearm. There's definite response. If I was looking in the mirror, moving my right hand I could feel and indeed observe flickers in my arm.... It was probably about the second or third session I think. [Interview participant 38, mirror therapy].

Another commonly cited advantage of both mirror therapy and the lower limb exercises was that it enabled participants to see their progress which motivated them to continue with the therapy: "My fingers started to move better... it made you feel as though you were getting somewhere. That kind of encouraged me to do the exercises" [Interview participant 38, mirror therapy].

Other participants reported that it "stimulated the brain to communicate with my limb" [Questionnaire Participant 22, lower limb exercises]; made their brain "think with two hands instead of one hand" after a few days [Interview participant 64 mirror therapy] and muscles "stronger or more reactive" which made the "physio exercises easier' [Questionnaire Participants 72 and 78, lower limb exercises]. This helped participants to move on with their goals. More generic physical effects were also reported including greater relaxation, sensation and more awareness of the limb and enhanced concentration.

Connected to this was a beneficial impact on autonomy; the patient-led therapy helped participants feel there was something they could do to help themselves and take some control of their situation. For example, one participant stated positively, in their questionnaire, that it was the "first decision I made for myself [since their stroke]'. (Questionnaire Participant 50, lower limb exercises), while another felt it was "important to do all you can to get back to normal" (Interview Participant 31, mirror therapy). Six participants specifically reported that they had a more altruistic benefit and were motivated by the opportunity to "have helped future people". For others, patient-led therapy provided an opportunity to keep occupied and boredom at bay:

It's a good distraction from worrying and stressing about it to just sit down quietly and do something about it.... You needed something to try and occupy yourself and try to do something because otherwise...the days were awful. So actually having to try and do something or try to achieve something I thought was a good idea. [Interview Participant 3, mirror therapy]

\section{Practical difficulties with patient-directed therapy}

Not all the reports were positive. The most frequently reported difficulty was "getting started". Responses from the questionnaires and interviews revealed these included difficulty setting up the equipment (mirror and/or exercise booklet) and getting in the correct position (particularly their weak arm); lack of space on the bedside table for the mirror and lack of supervision or support from others. Suggestions to overcome these problems included

- more space,

- a larger table,

- corner protectors and suckers on the mirrors to hold it in place,

- a lighter booklet and mirror so it could be manipulated with one hand and

- a clearer indication of number of repetitions required in the booklets.

The most commonly suggested solution was for greater input from staff to provide more physical assistance and supervision. Participants wanted someone to be more clearly present to 
physically help them, provide instruction and maintain motivation and focus:

You tended to get left alone to your own devices, and I think sometimes it would have just been, you know, a little prompt keeping people going ...... and remind to do the exercises .... It's hard to self-motivate, you know, to keep going [Interview Participant 50, mirror therapy]

Five participants mentioned that they involved their family and visitors to assist them.... This helped them with practical difficulties with "set up" but also provided greater focus and motivation

As long as you've got someone with you, that's fine, but if, you know, if you're on your own, it's a little bit harder... Some of my family learnt them as well. If I wasn't working with it one day, at least somebody was there to help, because I used to get a bit muddled! [Interview Participant 6, mirror therapy]

Four interviewees reported that they gave up trying to use the mirror on the bedside table and moved to a larger table and more peaceful environment: "The nurses allowed me to go into a separate room which had a bigger table and you could wheel a wheelchair into it etc. That was a lot better" [Interview Participant 54, mirror therapy].

Several participants who took a mirror home (if they were discharged before 4 weeks of treatment was complete) found it easier to do the mirror therapy at home where there was more space, time and help available from family.

\section{Barriers to patient-led therapy}

When participants expressed a negative view about the patient-led therapy, this was most frequently that they found it frustrating and/or boring:

After a bit you get bored...you were repeating, repeating... you constantly are up and down and, say well lifting fingers and that, for half an hour that is so boring. [Interview Participant 34, mirror therapy].

Others described how adherence tailed off as they failed to see results:

I continued to get these little flickers, but they weren't getting any stronger or more regular or anything like that, and eventually I must admit my use of the system declined a bit. [Interview Participant 39, mirror therapy].

This was a particular issue for the mirror therapy group. Despite giving informed consent to undertake 28 days of therapy, several participants stopped doing the exercises as they did not did not see "the point of the mirror", describing it as a "silly idea" which "could not possibly work" [Questionnaire Participants $68,69,70,71]$. Several reported that they did not adhere to the therapy as they were unconvinced by the visual illusion of the weak upper limb moving: "Well, it didn't kid me that it was my left arm that was working, because I knew it wasn't', [Interview Participant 38, mirror therapy]. Interview Participant 76 reiterated this view "I was thinking to myself, my brains not stupid enough to con itself into thinking that this is the other hand because I can't do it'. Some participants abandoned the mirror and continued to exercise in a conventional manner without it.

Other barriers to self-directed therapy related to the impact of the stroke. Several felt overwhelmed by the stroke and (despite giving informed consent) were unable to contemplate taking on something in addition to their usual care, describing the interventions as "too early" or "too much" [Questionnaire Participants 74,17,22,28,41,11]. Interview Participant 61 (mirror therapy) explained in more detail: "Your project on top of that [trying hard in physio], I thought would have been a bit too much for me.... I've got enough on my plate trying to deal with the difficulties",

Other stroke-related problems such as shoulder pain, limited memory, poor concentration and fatigue prevented some participants performing the exercises. Others preferred to focus on other areas of recovery, such as mobility. Several participants were uncomfortable about working independently, preferring to work in a group (for peer support and to overcome boredom) or with a therapist as they were concerned that the self-led therapy would in some way contradict or duplicate their " proper"' treatment:

I was basically doing the same exercises with the physio. That was really counterproductive; I'd have thought I was just countermanding what they were doing in the physio room.... So I didn't feel the incentive to carry on doing it. That's why, basically, at the end of the day, I gave up on it. [Interview Participant 62, lower limb exercises]

Many respondents felt their mood and attitude was important; both positively and negatively. It was difficult to maintain motivation when feeling low: "Sometimes I felt it was a bit of a drag, you know. If you weren't feeling particularly enthusiastic with yourself', [Interview Participant 38, mirror therapy]. Others simply reported being overwhelmed by the physical effects of stroke, which left them feeling generally unmotivated:

You know, you've got to have some motivation to do these things, to try and do it yourself when you've had a stroke is exceptionally difficult [Interview Participant 62, lower limb exercises]. because life is suddenly very difficult.... And that you can't do things that you always could do, and everything becomes so much more difficult. [Interview Participant 38, mirror therapy].

Patient-led therapy (and therapy in general) was not always perceived positively. In the questionnaires, participants described such therapy as "hard work but worth it" [Questionnaire Participants 60,29,5); a "necessary evil", [Questionnaire Participant 42] or "a means to an end" [Questionnaire Participant 40] that required reserves of determination and motivation which they observed that other patients did not always have: "I was trying very hard, I mean, a lot of people didn't seem to bother' [Interview Participant 34 mirror therapy]. However, "external" motivation from family and friends helped to promote uptake and adherence to the therapy: "Sometimes I felt it was a bit of a drag, you know. If you weren't feeling particularly enthusiastic with yourself... she encouraged me [granddaughter] ... you need a bit of encouragement...' [Interview Participant 38, mirror therapy].

\section{Discussion}

Our results indicate that patient-led therapy during in-patient stroke care is feasible and acceptable to patients. Nevertheless, it does not suit every one. Light touch supervision is needed, particularly for those with more severe disabilities while others would prefer some degree of supervision to provide focus, maintain motivation, deal with any problems and allay concerns. However, this does not need to be provided by qualified staff members; supervision by patients' visitors or group sessions were 
suggested, and could be used systematically in future trials and clinical practice.

Many patients felt that taking responsibility for their treatment gave them a sense of autonomy when they had little other control over their daily lives, but others felt too overwhelmed by the emotional impact or the physical effects of the stroke to take this on board. Another, unexpected, benefit was that patients felt encouraged and motivated by seeing their progress "for themselves'. Lack of information about progress is a frequent cause of patients' dissatisfaction with stroke services [18] and it appears these patient-led treatment regimens provided feedback that patients wanted. This could be adopted formally into clinical practice by including clear, quantitative markers of progress through validated measurement tools, or less formal measures such as the number of repetitions completed.

Conversely, several participants felt demotivated by a lack of visible results and described how their adherence tailed off as a consequence, in a similar way to descriptions of patient-led mirror therapy for people with chronic pain syndromes [19]. Given that post-stroke recovery is often incomplete, particularly in the upper limb [20], this could be an important element in patients' process of realisation and adaptation to partial recovery.

Adherence to any type of exercise is a challenge for many, whether able-bodied or disabled. Yet, it is rarely considered in stroke rehabilitation trials or clinical practice, perhaps because therapy and exercise is usually directly supervised by health care professionals which would maintain adherence. As communitybased rehabilitation and patient-led interventions become more widely used, further research is needed to consider how the extensive literature on adherence to exercise and physical activity could be applied to stroke rehabilitation and long-term support, and to evaluate its impact.

A clear message from the participants was that some were not convinced by the idea of mirror therapy and the illusion of the weak hand moving, consequently they stopped doing the mirror therapy (although some continued with the exercises without the mirror). It is known that an ability to believe in the illusion is essential for effective mirror therapy in chronic pain conditions [19] and a similar process may be at work for people with stroke. This suggests that selection of stroke survivors for whom mirror therapy may be helpful needs to be based on more than mere motor or activity limitations, as is the current case: The ability to believe in the mirror illusion should also be included as a selection criterion. For patient-led therapy, the patient's ability to work independently also needs to be considered more objectively and strategies to support it put in place if necessary. The development of a screening tool to cover these factors as well as the more common selection criteria based on stroke-related impairments may help to identify patients who would benefit most from patient-led therapies

To the authors "knowledge, this is the first report of the patients" perspective of patient-led (also referred to as selfdirected) therapy, be it mirror therapy or exercises. Our use of a mixed methods design has enabled a broader, more complete picture to emerge than that presented by a single method [21]. This has provided useful information concerning the implementation of patient-led therapies for future trials and clinical practice. Like all the qualitative research, the generalizability of the results is a potential limitation. However, as our selection criteria were broad and the sample size relatively large, we are confident that our results are reasonably representative. An additional limitation is that the research teams helped many participants complete the questionnaires and participants may have felt inhibited to give a less than positive response. However, the frank responses in some of the questionnaires belie this concern. Many stroke survivors struggle to give their feedback due to upper limb weakness, cognitive and/or communication difficulties but it is important that they are not excluded. Thus, we offered assistance where necessary but encouraged the participants to be frank.

\section{Declaration of interest}

The authors report no conflicts of interest. This article presents independent research funded by the National Institute for Health Research (NIHR) under its Research for Patient Benefit (RfPB) Programme (Grant Reference Number PB-PG-1208-18077). The views expressed are those of the authors and not necessarily those of the NHS, the NIHR or the Department of Health.

\section{References}

1. Van Peppen R, Kwakkel G, Wood-Dauphinee S, et al. The impact of physical therapy on functional outcomes after stroke: what's the evidence? Clin Rehabil 2004;18:833-62.

2. Kwakkel G, Van Peppen R, Wagenaar R, et al. Effects of augmented exercise therapy time after stroke: a meta-analysis. Stroke 2004;35: 2529-36.

3. Intercollegiate Stroke Working Party. National clinical guideline for stroke. 4th ed. London: Royal College of Physicians; 2012.

4. West T, Bernhardt J. Physical activity in hospitalised stroke patients. Stroke Res Treat 2012;2012:813765.

5. Bernhardt J, Dewey H, Thrift A, et al. Inactive and alone: physical activity within the first 14 days of acute stroke unit care. Stroke 2004;35:1005-9.

6. Tinson DJ. How stroke patients spend their days: an observational study of the treatment regime offered to patients in hospital with movement disorders following stroke. Disabil Rehabil 1989;11: 45-9.

7. De Wit L, Putman K, Dejaeger E, et al. Use of time by stroke patients: a comparison of four European rehabilitation centers. Stroke 2005;36:1977-83.

8. Skarin M, Sjöholm, A, Nilsson A, et al. A mapping study on physical activity in stroke rehabilitation: establishing the baseline. J Rehab Med 2013;45:997-1003.

9. Royal College of Physicians. National Sentinel Stroke Audit. Phase I (Organisational Audit) and Phase II (Clinical Audit) 2010. Prepared on behalf of the Intercollegiate Stroke Working Party. London: Royal College of Physicians; 2010. Available from: https://www. rcplondon.ac.uk/sites/default/files/2010-stroke-public-report.pdf [last accessed 11 Mar 2015].

10. Harris JE, Eng JJ, Miller WC, et al. A Self-Administered Graded Repetitive Arm Supplementary Program (GRASP) improves arm function during inpatient stroke rehabilitation. A multi-site randomized controlled trial. Stroke 2009;40:2123-8.

11. Langhammer B, Stanghelle JK, Lindmark B. An evaluation of two different exercise regimes during the first year following stroke: a randomised controlled trial. Physiother Theory Pract 2009;25: $55-68$.

12. Tyson SF, Wilkinson J, Thomas N, et al. Phase II randomized controlled trial of patient-led mirror therapy and lower limb exercises in acute stroke. Neurorehabil Neural Repair 2015; In press.

13. Horne M, Thomas N, Vail A, et al. Staff's views of delivering patient-led therapy during in-patient stroke rehabilitation: a focus group study with lesson for trial fidelity. Trials 2015; In press.

14. Patton MQ. Qualitative evaluation and research methods. 3rd ed. Newbury Park (CA): Sage Publications; 2002.

15. Bowling A. Research methods in health: investigating health and health services. 3rd ed. Philladelphia: Open University; 2009.

16. Hsieh H, Shannon SE. Three approaches to qualitative content analysis. Qual Health Res 2005;15:1227-88.

17. Ritchie J, Spencer L, O'Connor W. Carrying out qualitative analysis. In: Ritchie J, Lewis J, eds. Qualitative research practice: a guide for social science students and researchers. Thousand Oaks: Sage; 2003:219-62.

18. Tyson S, Burton L, McGovern A. Services users' views and experiences of the assessment process in stroke rehabilitation. Clin Rehabil 2014;28:824-31.

19. McCabe C. Mirror visual feedback therapy: a practical approach. J Hand Ther 2011;24:170-9. 
20. Nakayama HJ, Jørgensen HKS, Raaschou HO, Olsen TS. Recovery of upper extremity function in stroke patients: the Copenhagen Stroke Study. Arch Phys Med Rehabil 1994;75:394-8.

21. Johnson RB, Onwuegbuzie AJ, Turner LA. Toward a definition of mixed methods research. J Mixed Meth Res 2007;1:112-33.

\section{Appendix 1. The interview schedule}

(1) Can you tell me about your experiences of mirror therapy? Probes: How did that make you feel? Explain

What concerns, if any, did you have? Explain Was your ability to perform mirror therapy assessed? What did you not like?

(2) Did you have any difficulties setting up the mirror? Probes: Explain

Did you need help?

Did the health care professionals assist you?

(3) Did you experience any problems with the exercise booklet? Probes: Explain

Where there things you didn't understand?
(4) Could you do the exercises you were given? Probes: What difficulties did you experience? Explain

(5) Did you feel any benefits from doing the exercises?

Probe: How useful did you find the exercises you were given? Explain

How did it make you feel? Explain

Did you enjoy doing the exercises?

Would you recommend the exercises to other stroke survivors?

(6) How do you think we could improve the exercise booklet you were given?

Probe: How could it be done better? Explain

(7) How do you think we could improve the exercises you were given?

Probe: How could it be done better? Explain

(8) Do you feel the exercises worked? Probes: Explain

How important is this?

(9) Is there anything else that I have failed to ask you in this interview which you feel is important for me to know?

(10) Is there anything else that you would like to add? 